\title{
SISTEMA NACIONAL DE PÓS-GRADUAÇÃo E A ÁREA DE QUÍMICA NA CAPES
}

\author{
Adriano L. Monteiro ${ }^{\mathrm{a}, *}$, Maysa Furlan ${ }^{\mathrm{b}}$ e Paulo A. Z. Suarez \\ a'Departamento de Química Orgânica, Instituto de Química,. Universidade Federal do Rio Grande do Sul, Av. Bento Gonçalves \\ 9500, CP 15003, 91501-970 Porto Alegre -RS, Brasil \\ bDepartamento de Química Orgânica, Instituto de Química, Universidade. Estadual Paulista, Av. Prof. Francisco Degni 55, CP 35, \\ 14800-900 Araraquara - SP, Brasil \\ 'Instituto de Química, Universidade de Brasília, Campus Universitário Darcy Ribeiro, CP 4478, 70904-970 Brasília - DF, Brasil.
}

Recebido em 04/04/2017; aceito em 16/05/2017

\begin{abstract}
NATIONAL POSTGRADUATE SYSTEM (SNPG) AND CHEMISTRY AREA AT THE BRAZILIAN FEDERAL AGENCY FOR POST-GRADUATE EDUCATION (CAPES). The Coordination for the Improvement of High Education Personnel (CAPES), the Brazilian federal agency for graduate programs, plays a fundamental role for the expansion and consolidation of the National Postgraduate System (SNPG) and the execution of the National Graduate Plan (PNPG) 2011-2020. In this paper, we discuss the evolution of the Brazilian graduate program in chemistry and its role in the formation of highly qualified professionals in chemistry (academic master's degree, professional master's degree and doctoral degree) for the academy, teachers and lecturers for all levels of the education system, as well for the non-academic market.
\end{abstract}

Keywords: National Postgraduate System, CAPES, graduate programs, chemistry

\section{INTRODUÇÃO}

A Coordenação de aperfeiçoamento de pessoal de nível superior (CAPES) foi criada em 1951. ${ }^{1}$ Tem como principal premissa contribuir para a formação de recursos humanos qualificados para setores acadêmicos e não acadêmicos da sociedade, de tal forma a fortalecer as bases científicas, tecnológicas e de inovação intrínsecas ao Sistema Nacional de Pós-Graduação (SNPG) do país. Para tanto, desde 1976 avalia periodicamente os programas de pós-graduação stricto sensu com vistas a qualificar, orientar e induzir expansões do sistema. ${ }^{2} \mathrm{~A}$ avaliação é feita por pares e baseada em critérios e ferramentas estabelecidos com a participação ativa da comunidade acadêmica. A avaliação é fundamental para alcançar e manter a qualidade do SNPG, além de fornecer subsídios para o financiamento dos Programas de Pós-Graduação do país. Os critérios são aprimorados a cada avaliação, sempre buscando privilegiar a formação de profissionais voltados às necessidades da sociedade e do país. De toda forma, uma análise atual demonstra a necessidade de adequação em alguns aspectos temporais e estruturais da avaliação. A avaliação do impacto da Pós-Graduação (PG) na formação de recursos humanos, com a introdução de indicadores de resultado e a diminuição de indicadores quantitativos, é condição sine qua non como resposta às expectativas de retorno à sociedade do investimento realizado. Nesse contexto, a área de Química tem tido um papel de vanguarda na utilização desses indicadores, principalmente para a avaliação dos Programas considerados de excelência internacional (Notas 6 e 7). ${ }^{3}$ É importante também destacar que a internacionalização, a interdisciplinaridade e o apoio a outros níveis de ensino se configuram entre os principais eixos que compõem o PNPG/2011-2020, subsidiados pela criação de uma agenda nacional de pesquisa. ${ }^{4} \mathrm{As}$ atividades de internacionalização tem sido ampliadas nos últimos anos e a participação dos órgãos de fomento no financiamento de projetos em colaboração com pesquisadores estrangeiros e bolsas para o desenvolvimento de pesquisa no exterior, alavancou sobremaneira a inserção internacional de docentes e discentes da pós-graduação. Com

*e-mail: adriano.monteiro@ufrgs.br isso, os Programas de Pós-Graduação (PPGs) consolidados da área de Química já demonstram atividades em resposta a tais processos, e colaborações internacionais, intercâmbio de discentes/docentes e pós-doutorandos se intensificaram nos últimos anos, qualificando a produção científica. A Química, como ciência central, tem forte interação com áreas afins, propiciando a formação de recursos humanos com forte enfoque interdisciplinar, refletindo na qualificação da produção científica, na autonomia desses profissionais e na inovação como produto da criatividade inerente a esse processo. Ao buscar a compreensão da matéria em nível molecular, a Química se torna a ciência central que impacta as diversas áreas do conhecimento que tratam dos seres vivos, energia e ambiente. Áreas como Medicina, Física, Engenharias, Ensino, Biotecnologia, Biologia, Bioquímica, Neurociência, Farmacologia, Agronomia, Ciências dos Materiais, Nanociência, Ciência Ambiental, entre outras, necessitam das teorias e metodologias da Química. Na pós-graduação muitos cursos utilizam as subáreas clássicas, Físico-Química (FQ), Química Analítica (QA), Química Inorgânica (QI) e Química Orgânica (QO), como áreas de concentração que constituem o referencial teórico necessário para o alicerce do conhecimento químico. Essas importantes abordagens refletem e refletirão na qualificação da produção científica e na inovação como produtos da criatividade.

O ensino fundamental e médio apresenta índices preocupantes e, sem dúvida, a educação básica é um dos maiores desafios para o Brasil. Uma preocupação constante na área de Química é avaliar o reflexo da qualidade da produção científica na educação em Química. No Brasil, há um grande contingente de analfabetos de diferentes categorias, elevado percentual de professores leigos, inclusive de Química, jovens entre 18-30 anos fora da Universidade e outros entre 25-33 anos fora da pós-graduação. O desestímulo dos estudantes e as altas taxas de evasão culminam no despreparo de jovens para o mercado de trabalho e para a universidade. Nesse contexto, a melhoria da educação básica é um dos maiores desafios para todo o Sistema Nacional de Pós-Graduação (SNPG) e para a área de Química. Assim, a área vem buscando ampliar a interação dos programas de pós-graduação com os cursos de licenciatura, no sentido de promover a melhoria da qualidade da formação dos professores e estimular a 
participação de programas de pós-graduação nas questões relativas à melhoria da qualidade da educação básica. O Mestrado Profissional em Matemática em rede Nacional PROFMAT, aprovado no CTC-ES da CAPES em 2010, visa atender aos professores de matemática em exercício no ensino básico, especialmente na escola pública, que pretendam aprimorar sua formação docente aprofundando os conteúdos do seu domínio. ${ }^{5}$ Desde então, A CAPES vem induzindo a criação de programas de mestrado profissional em rede nacional nas diferentes áreas envolvendo o ensino fundamental. Nesse sentido, a área apoiou a formulação de um mestrado profissional em ensino de química em rede nacional (PROFQUI), cujo processo de formatação da proposta foi conduzido pela SBQ. O programa foi aprovado em 2015 e tem início previsto para o segundo semestre de 2017.

A CAPES ao desenvolver ações em prol do ensino básico dá um grande passo em direção ao futuro. Nesse contexto, é fundamental que os docentes da pós-graduação participem ativamente desse processo e algumas sugestões para a melhoria do Ensino de Química podem ser apontadas, como a valorização da carreira do magistério; a manutenção e ampliação de projetos como o Programa Institucional de Bolsa de Iniciação à Docência (PIBID) para a formação inicial dos professores; o incentivo à formação continuada dos professores em programas de pós-graduação com concessão de bolsas; a ampliação da oferta de mestrado profissional voltado para a formação de professores das redes de ensino fundamental e médio; e o incentivo do contato de alunos da educação básica com laboratórios, pesquisadores e alunos de pós-graduação via programas do tipo iniciação científica júnior.

Dentre os principais desafios da Pós-Graduação brasileira apontados pelo Plano Nacional de Pós-Graduação 2011-2020, estão a diminuição das assimetrias centradas principalmente nas regiões Centro-Oeste, Norte e Nordeste e, no âmbito do aperfeiçoamento da avaliação, incorporar a avaliação do destino dos egressos. Considerar o valor dos egressos na avaliação sempre foi uma preocupação da área de Química, mas esbarrava na dificuldade em se conseguir dados consistentes e abrangentes. Atualmente, a CAPES e CGEE concluíram o levantamento dos egressos que atuam no mercado de trabalho e criaram ferramentas que permitem a avaliação da empregabilidade dos mesmos, dimensionando assim o impacto econômico e social de cada PPG. Espera-se com esse estudo, a inclusão de um indicador qualitativo para contribuir na avaliação da formação dos recursos humanos.

As revistas editadas pela Sociedade Brasileira de Química (SBQ) rapidamente se consolidaram como meio de divulgação da pesquisa em química no país, estão presentes na produção científica declarada por todos os programas de pós-graduação na área e sempre foram valorizadas na avaliação dos programas. Em particular, a revista Química Nova que possibilitou a divulgação das pesquisas desenvolvidas no Brasil em português, também buscou focar temas relevantes relativos pós-graduação em química, seja discutindo o papel da SBQ, a avaliação dos programas de pós-graduação na forma de artigos e editorias. ${ }^{6-13}$ Embora não faça parte do escopo do Journal of the Brazilian Chemical Society da SBQ, que divulga os trabalhos de pesquisa em inglês, o periódico tem contribuído com a discussão da pós-graduação em química no país por meio de seus editoriais. ${ }^{14-16}$

Visando uma melhor comunicação e transparência, a CAPES criou uma página para cada área de avaliação, na qual estão acessíveis os documentos de área e relatório de avalição desde a Trienal 2010, critérios para submissão de novas propostas (APCN), atualizações e critérios qualis e seminários de acompanhamento. ${ }^{17}$ Embora várias informações sobre os programas da área estejam disponibilizadas pela CAPES, nesse artigo pretende-se abordar a evolução e o estado da arte dos programas de pós-graduação da área de Química e o seu papel na formação de recursos humanos qualificados, indispensáveis para o desenvolvimento sustentável do país.

\section{Evolução e estado da arte da área de Química da CAPES}

A área de Química é uma das mais antigas na Coordenação de Aperfeiçoamento de Pessoal de Nível Superior (CAPES) e teve seus primeiros programas de pós-graduação criados na década de 60 . A média de crescimento do número de programas da área foi de cerca de 8-9 programas/década até o final do século passado (Tabela 1$).{ }^{18} \mathrm{~A}$ partir do ano 2000 o número de programas triplicou, principalmente devido a expansão do sistema universitário federal, via Programa de Apoio a Planos de Reestruturação e Expansão das Universidades Federais, associado ao apoio fundamental da CAPES ao crescimento, consolidação e internacionalização do sistema de pós-graduação brasileiro. Essa forte participação e integração da área de Química nos principais aspectos contemporâneos discutidos no PNPG a torna pioneira na proposição de critérios e ações que têm contribuído sobremaneira para a evolução e consolidação da pós-graduação do país.

Na última avaliação, triênio 2010-2012, constavam 61 PPGs (Tabela 1), dos quais 13 receberam notas 6 e 7 (22\%); 12 nota 5 (18\%); 19 nota 4 (36\%); 14 nota $3(25 \%)$ e 1 nota 2 (Figura 1$).{ }^{3}$ Os 2 Programas de mestrado profissional receberam nota 4 . Desde a avaliação do triênio 1998-2000, a área mostrou um aumento significativo de Programas (Tabela 1), incluindo a criação de novos cursos em regiões que não apresentavam oportunidades de formação em nível de pós-graduação na área. É importante destacar a indução que ocorreu nos anos 2000 para que instituições de ensino (USP-SP, USP-SC, UFRJ, UFF e UFC) que apresentavam mais de um programa de pós-graduação, geralmente alicerçados em seus Departamentos, fizessem a fusão dos mesmos em um programa de química. A fusão dos referidos programas permitiu o alinhamento dos mesmos com os novos preceitos da pós-graduação contemporânea e dos objetivos do PNPG, que destaca a importância da formação de redes interdisciplinares em detrimento a uma visão disciplinar, de forma a qualificar e internacionalizar as pesquisas envolvidas na formação de recursos humanos.

Atualmente, a área da Química é composta por 70 Programas de Pós-Graduação (PPGs) recomendados pela CAPES em andamento (Tabela 1). ${ }^{19}$ São 114 cursos: sendo 67 cursos de Mestrado Acadêmico (ME), 45 cursos de Doutorado (DO) e 2 Mestrados Profissionais (MP), distribuídos em quase todos os estados brasileiros. No total, a área possui 44 programas com Mestrado e Doutorado, 23 Programas só com mestrado acadêmico, 1 Programa só com Doutorado e 2 Programas com Mestrado Profissional (Tabela 2).

Os Programas estão distribuídos em todas as regiões do país, sendo 5 na Região Norte, 18 na Região Nordeste, 12 na Região Centro-Oeste, 46 na Região Sudeste e 19 na Região Sul (Tabela 2 e Figura 2), mostrando assimetria na distribuição dos programas de PG/ Química pelo território nacional e boa correlação com a distribuição do número de cursos/ano de PG nas diferentes áreas do saber, nas mesmas regiões do país. Somente quatro (4) estados da região norte (Acre, Amapá, Rondônia e Tocantins) ainda não possuem programas de pós-graduação em Química. Dos estados com programa(s) na área, somente três (3) não têm curso de doutorado em Química, a saber Maranhão, Roraima e Mato Grosso.

No período 2013-2016 foram iniciados 7 novos programas de mestrado e 7 novos cursos de doutorado em programas que só tinham o curso de mestrado. Em termos de pós-graduação em rede, em 2014 foi criado o Programa de Pós-Graduação Multicêntrico em Química de Minas Gerais nos níveis de mestrado e doutorado que conta, atualmente, com 3 IES nucleadoras e 11 IES associadas. Recentemente, o Mestrado Profissional em Química em Rede Nacional (PROFQUI) foi aprovado e está em fase de implantação. São 22 IES participantes distribuídas nas regiões centro-oeste, nordeste, sul e sudeste, tendo como sede a UFRJ. No segundo semestre de 2016, foi aprovado 


\section{Distribuição de Notas - Química}

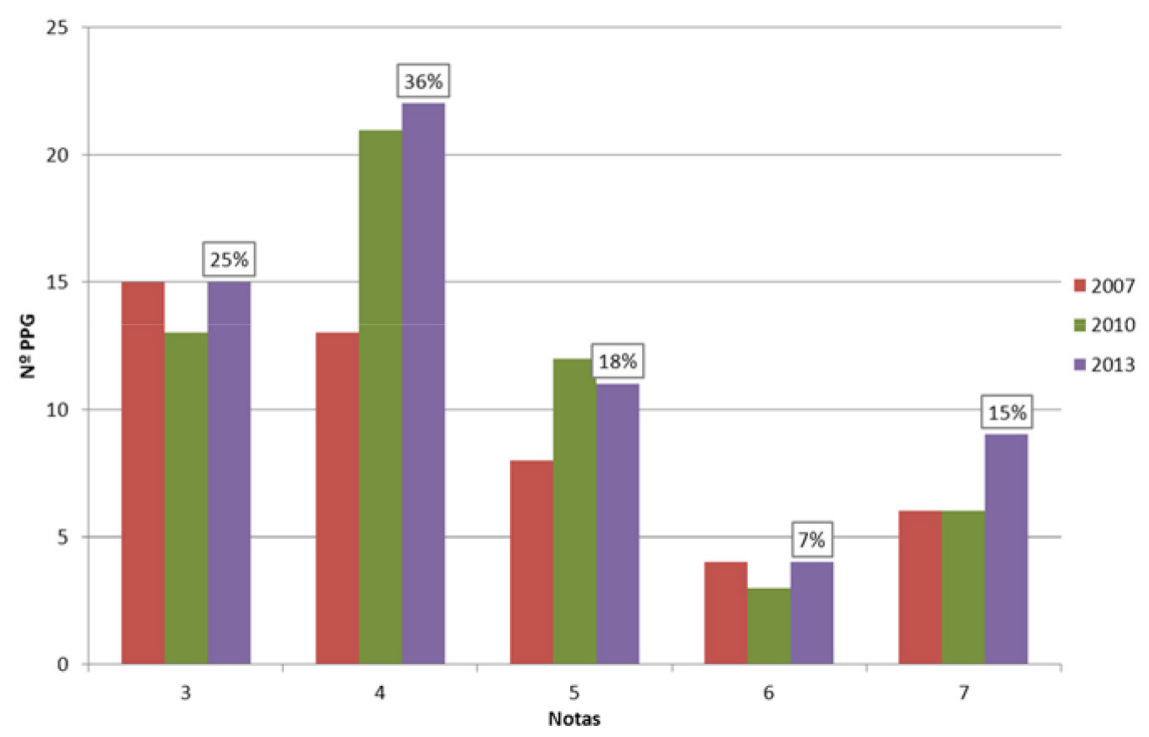

Figura 1. Distribuição das notas da área de Química nas últimas avaliações periódicas ${ }^{3}$

Tabela 1. Histórico da criação dos programas de pós-graduação da Área de Química e número de programas avaliados desde $1998^{19}$

\begin{tabular}{cccc}
\hline Período & $\begin{array}{c}\text { Programas } \\
\text { criados }\end{array}$ & Período & $\begin{array}{c}\text { Programas } \\
\text { avaliados }\end{array}$ \\
\hline $1963-1969$ & 8 & $1998-2000$ & 40 \\
$1970-1979$ & 7 & $2001-2003$ & 44 \\
$1980-1989$ & 9 & $2004-2006$ & 51 \\
$1990-1999$ & 9 & $2007-2009$ & 58 \\
$2000-2009$ & 24 & $2010-2012$ & 61 \\
$2010-2016$ & 16 & $2013-2016$ & 69 \\
\hline
\end{tabular}

Tabela 2. Distribuição dos Programas de Pós-graduação da Área de Química em função das regiões e modalidades ${ }^{19}$

\begin{tabular}{lccccc}
\hline Região & ME & MP & DO & ME/DO & Total \\
\hline Centro-Oeste & 4 & 0 & 0 & 3 & 7 \\
Nordeste & 8 & 0 & 0 & 9 & 17 \\
Norte & 2 & 0 & 0 & 2 & 4 \\
Sudeste & 2 & 2 & 0 & 23 & 27 \\
Sul & 7 & 0 & 1 & 7 & 15 \\
\hline Brasil & 23 & 2 & 1 & 44 & 70 \\
\hline
\end{tabular}

no Conselho Técnico Científico da CAPES a criação de dois novos mestrados, ambos na região norte (UFT e UNIFESSPA), e dois novos doutorados: um no programa de mestrado da UEL e o outro uma associação de três instituições da região Centro-Oeste (UFGD, UFG-Campus Catalão e UEG) que tem mestrado em funcionamento. Os novos cursos da região norte abriram edital de seleção para o primeiro semestre de 2017. Com isso, a área de química não terá programas de pós-graduação somente em três estados da região norte (Acre, Amapá e Rondônia).

Dados de 2015 (Plataforma GEOCAPES; 14/02/2017) apontam para um total de 5935 cursos de PG no país, em todas as áreas do conhecimento, correspondendo a uma percentagem de $57,6 \%$ de cursos de mestrado, $34 \%$ de doutorado e $9 \%$ de mestrado profissional. Uma análise da área de Química mostra correspondente percentual

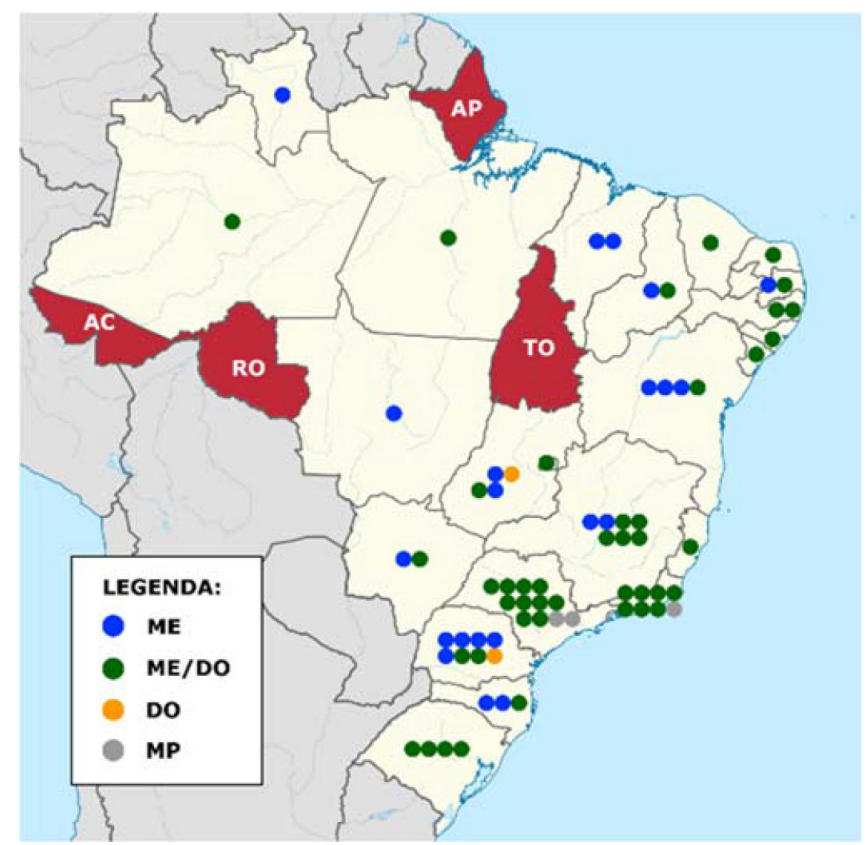

Figura 2. Distribuição dos programas de pós-graduação da área de Química em $2016^{19}$

de cursos de mestrado $(57,0 \%)$ e percentual superior de cursos de doutorado $(40,4 \%)$, quando comparados a média nacional. A mesma análise mostra que a área tem espaço para crescer em número de cursos de mestrado profissional $(2 \%)$, principalmente pela sua característica multi- e interdisciplinar e consequente fronteira com as áreas tecnológicas, biológicas e saúde.

Embora os indicadores de número de alunos, mestres e doutores titulados e produção científica mostrasse um aumento, o número de docentes atuando na pós-graduação em química manteve-se estagnado em aproximadamente 900 docentes do início da década de 90 até 2005 . A figura 3 mostra a evolução do quadro de docentes a partir de 2004, quando se passou a usar a denominação de docentes permanentes, colaboradores e visitantes. O número de docentes permanentes era de 940 em 2004 e foi aumentando linearmente até 2010 quando chegou a 1331 docentes permanentes. A partir desse 
ano há uma inflexão na curva e o número e docentes permanentes salta para 1529 em 2011. Essa inflexão está relacionada a uma ação de indução da coordenação de área da Química, que em 2010 flexibilizou as regras de pontuação de modo a favorecer o credenciamento rápido de jovens docentes, não contabilizando no denominador vários quesitos na avaliação trienal 2013. ${ }^{13} \mathrm{Na}$ ocasião, foram considerados jovens docentes permanentes aqueles que haviam obtido o título de doutor a partir de 2006. A filosofia que motivou essa ação estava centrada em possibilitar que jovens docentes pudessem desenvolver seus trabalhos e, consequentemente, orientar na pós-graduação sem a cobrança imediata de resultados. A mesma política será mantida na Avaliação Quadrienal 2017 para os jovens docentes que obtiveram o doutorado a partir de $2009 .{ }^{18}$ Tal ação tem implicações saudáveis tanto para a renovação do PPGQ, quanto para a ascensão profissional do novo contratado. Pode-se notar que a agilidade em credenciar jovens docentes no quadro permanente agrega qualidade e permitiu saudável oxigenação na maioria dos programas da área. O impacto benéfico dessa política pioneira da área de química pode ser medido pelo número de docentes permanentes que passou para 1885 em 2015 (base GEOCAPES; 14/02/2017) e pelo interesse de outras áreas em aplicá-la na avaliação quadrienal 2017.

O número de mestres e doutores titulados no triênio 2010-2012 (média 924/ano e 444/ano, respectivamente) mostra uma contribuição de 1,29 e 0,56 de mestres e doutores titulados/mil habitantes na faixa etária de 24 a 65 anos. O relatório CGEE/2012 indica que o número médio de mestres e doutores titulados/mil habitantes na mesma faixa etária, nas diferentes áreas do conhecimento, era de 5,36 e 1,94, respectivamente. Os dados da área demonstram sua especial contribuição para a formação de mestres e doutores no país e, também, que há possibilidades de expansão. Com base nos dados da fonte GEOCAPES (14/02/2017), o número de mestres e doutores titulados no período de 2013-2015 demonstra forte evolução quando comparado ao triênio anterior (média 1058/ano e 568/ano, respectivamente). Como a avaliação atual passou a ser quadrienal, computados os dados de 2016, esse número será ainda mais expressivo. Na atualidade, os alunos de mestrado somam 2678 e de doutorado 3485, mostrando uma evolução no número de alunos matriculados em relação ao triênio 2010-2012, que apresentou média de 2477 e 2639, respectivamente, corroborando aumento consubstancial de matrículas no doutorado. A Figura 3 demonstra essa evolução a partir de 1998. É importante destacar que desde 1998 a área titulou 12450 mestres, sendo 75 na modalidade profissional, e 6795 doutores (fonte GEOCAPES; 14/02/2017). Em 1998 a área já tinha mais discentes matriculados no doutorado que no mestrado, o que é característico das áreas mais consolidadas. O forte aumento do número de programas nos anos 2000, incialmente de novos mestrados e na sequência de novos doutorados, fez com que o número de matriculados se igualasse em 2007 (Figura 4). De toda forma, o sistema se equilibrou e as matrículas de discentes de doutorado voltaram a aumentar a partir de 2009. Nessa perspectiva é possível notar que a partir de 2011 o número de discentes matriculados no mestrado se estabilizou e o número de discentes matriculados no doutorado demonstra aumento progressivo (Figura 4).

Paralelo ao crescimento de matrículas de mestrandos e doutorandos (Figura 4), desde o triênio 2007-2009 a área tem incorporado critérios qualitativos à avaliação de forma a contribuir com o modelo atual, com excelentes reflexos na formação de recursos humanos.

A avaliação realizada pela CAPES busca impulsionar todo o Sistema Nacional de Pós-Graduação (SNPG) para um padrão de excelência acadêmica para os mestrados e doutorados nacionais. ${ }^{1}$ Os resultados permitem propor metas e desafios que expressam os avanços da ciência e tecnologia. Com isso, a avaliação se configura na base para a formulação de políticas para o SNPG, bem como para o dimensionamento das ações de fomento ${ }^{4}$. O ponto central da avaliação é a qualidade da formação dos recursos humanos em nível de mestrado e doutorado do programa como um todo. Essa avaliação não deve ser confundida com a avaliação de pesquisadores ou grupos de pesquisa, objeto de avaliação de outras agências de fomento, como o CNPq. A avaliação de novos cursos de pós-graduação e dos cursos em andamento é muito mais complexa e multifacetada. A análise do perfil e atuação dos docentes, bem como de sua produção científica e/ ou tecnológica, precisa ser coerente com a proposta pedagógica, com as áreas de concentração e com as linhas de pesquisa e capacidade de orientação no seu sentido pleno. Na avaliação dos programas em andamento é fundamental avaliar o desempenho dos discentes e egressos de maneira a evidenciar se a formação do pós-graduando é

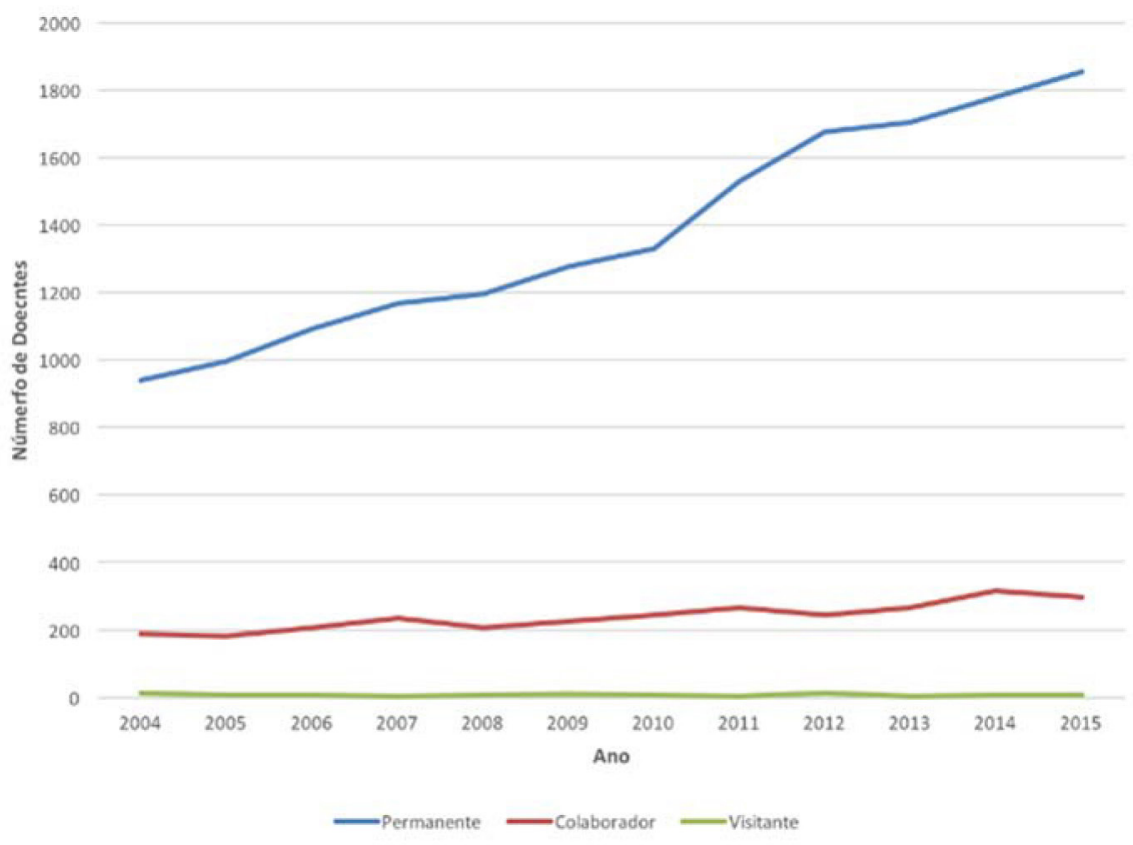

Figura 3. Docentes na área de Química 2004 a 2015 (fonte: GEOCAPES; 14/02/2017) 

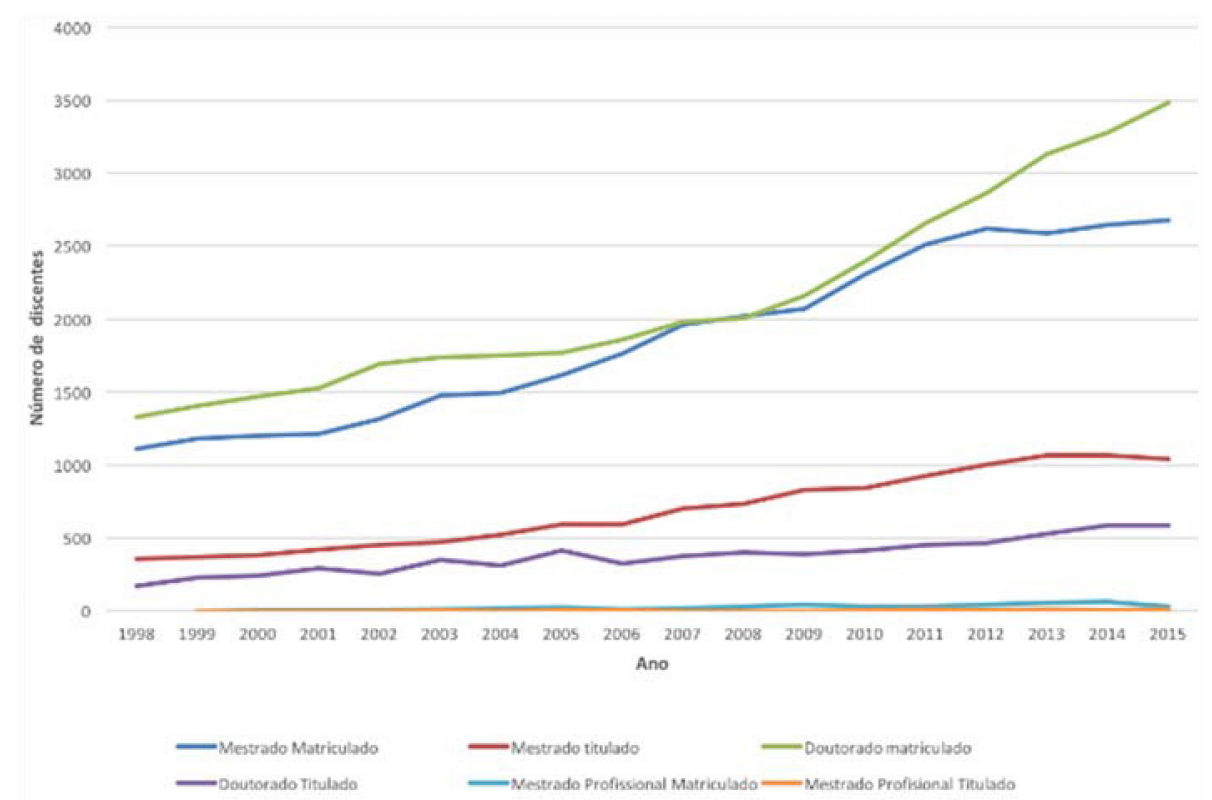

Figura 4. Evolução das matrículas e titulações de mestrado e doutorado a partir de 1998 (fonte: GEOCAPES; 14/02/2017)

abrangente e permite responder às demandas da sociedade tanto em termos locais, regionais e nacionais.

Desde 1976, quando se iniciou a avaliação dos programas stricto sensu, o sistema de avaliação passou por uma série de aperfeiçoamentos, sendo que os parâmetros de avaliação são constantemente aperfeiçoados em função da evolução e do crescimento da pós-graduação, da maturidade das áreas e do impacto da formação dos pós-graduandos em função das demandas da sociedade naquele período. ${ }^{1}$ Se no início da avaliação eram apenas 150 cursos de mestrado e doutorado em funcionamento (CAPES 60 anos), na Avaliação Trienal 2013, foram analisados 3.337 programas de pós-graduação, que compreendem 5.082 cursos, sendo 2.893 de mestrado, 1.792 de doutorado e 397 de mestrado profissional. ${ }^{20}$

Nesse contexto, o Qualis Periódicos tem como função auxiliar os comitês de avaliação no processo de análise e de qualificação da produção bibliográfica dos docentes e discentes dos programas de pós-graduação credenciados pela CAPES. ${ }^{21} \mathrm{O}$ Qualis Periódico de uma área é o conjunto de revistas em que os programas publicaram num determinado período e tem como finalidade a avaliação comparativa do conjunto das produções em termos de artigos dos programas da área no momento da avaliação. O Qualis Períodicos não é uma base referencial, não foi concebida para a avaliação de indivíduos, como por exemplo em concursos docentes, e sua utilização para tais fins pode trazer graves distorções. O surgimento do Qualis veio com o crescimento da pós-graduação e da produção científica brasileira. Com a crescente evolução do número de trabalhos publicados ficou claro que a contabilização na avaliação somente do número de artigos publicados não era suficiente e que novos critérios que qualificassem a produção dos programas deveriam ser incluídos. A primeira classificação do Qualis dividia os periódicos em três categorias: internacional, nacional e local. Para cada categoria os periódicos eram classificados em três estratos (A, B e C). A evolução da qualidade das publicações demonstrou que somente os três estratos, A, B e C, utilizados não mais demonstravam poder discriminatório e uma reformulação foi necessária. Com isso, sete estratos (A1, A2, B1, B2, B3, B4 e B5) foram introduzidos para qualificar os periódicos, além do estrato $\mathrm{C}$, no qual consta periódicos que a área não deveria considerar na avaliação. Para evitar a concentração de periódicos em poucos estratos foram adotadas algumas travas para os estratos superiores comuns a todas as áreas: somatório dos periódicos nos estratos A1, A2 e B1 menor ou igual a 50\%, somatório dos periódicos nos estratos A1 e A2 menor ou igual a $25 \%$. Nesse contexto, o número de periódicos no estrato A1 deve ser menor que o do estrato A2.

A figura 5 mostra a evolução da produção em periódicos científicos (média anual) para as avaliações inicialmente bienais (1990/91 a 1996/97) e, na sequência trienais (2001-03 a 2010-12). ${ }^{11,22}$ O número de artigos publicados na área tem aumentado significativamente e passou de 418 no biênio 90/91 para 3898, no triênio 10-12. Em termos de média de artigos publicados por docente, houve também aumento significativo até o triênio 2004-6. A partir desse momento, quando o número de docentes iniciou seu mais efetivo crescimento, a média de artigos por docente manteve-se constante ( 2,6 artigos/ docentes), mesmo com a inclusão expressiva dos jovens docentes na última trienal. Dados mais marcantes estão relacionados à evolução da qualidade dos periódicos em que a área pública. A tabela 3 mostra a estratificação da produção em periódicos da área de Química nas últimas quatro avaliações trienais e a classificação em função dos fatores de impacto do Journal of Citation Report. A mudança de estratificação para A1-B5 e a valorização da produção nos estratos superiores (Peso relativo dos estratos: $\mathrm{A} 1=10 ; \mathrm{A} 2=7,5 ; \mathrm{B} 1=5,5$; $\mathrm{B} 2=3 ; \mathrm{B} 3=2 ; \mathrm{B} 4=1 ; \mathrm{B} 5=0,5 ; \mathrm{C}=0$ ) levou a um deslocamento da produção para os periódicos de maior fator de impacto. Na Trienal 2004 o estrato superior IA apresentava as revistas com fator de impacto igual ou maior que 1 , representando $64,1 \%$ da produção total da área. Na trienal 2013 revistas com fator de impacto igual ou maior que 1 foram classificadas nos estratos B3 e superiores, representando $88,3 \%$ da produção total da área. $\mathrm{Na}$ trienal 2007, passou-se a considerar os periódicos com fator de impacto igual ou superior a 2 para o estrato IA, que representou $42,1 \%$ da produção total da área. Na estratificação de A1 a B5, periódicos com fator de impacto igual ou superior a 2 foram classificados de B2 a A1, representando 76,3 $\%$ e $77 \%$ nas trienais 2010 e 2013, respectivamente. Outra indução para a qualificação da produção foi considerar somente os artigos classificados no estrato A1 com participação discente na avaliação dos programas de excelência notas 6 e 7. Tanto na trienal 2010 como 2013 os periódicos com fator de impacto igual ou superior a 4 foram considerados A1, sendo que a proporção de artigos classificados em A1 passou de 6,3\% na Trienal 2010 para 11,5\% na Trienal 2013.

Para compor os critérios de avaliação, a área de Química considera majoritariamente e preferencialmente indicadores relacionados 


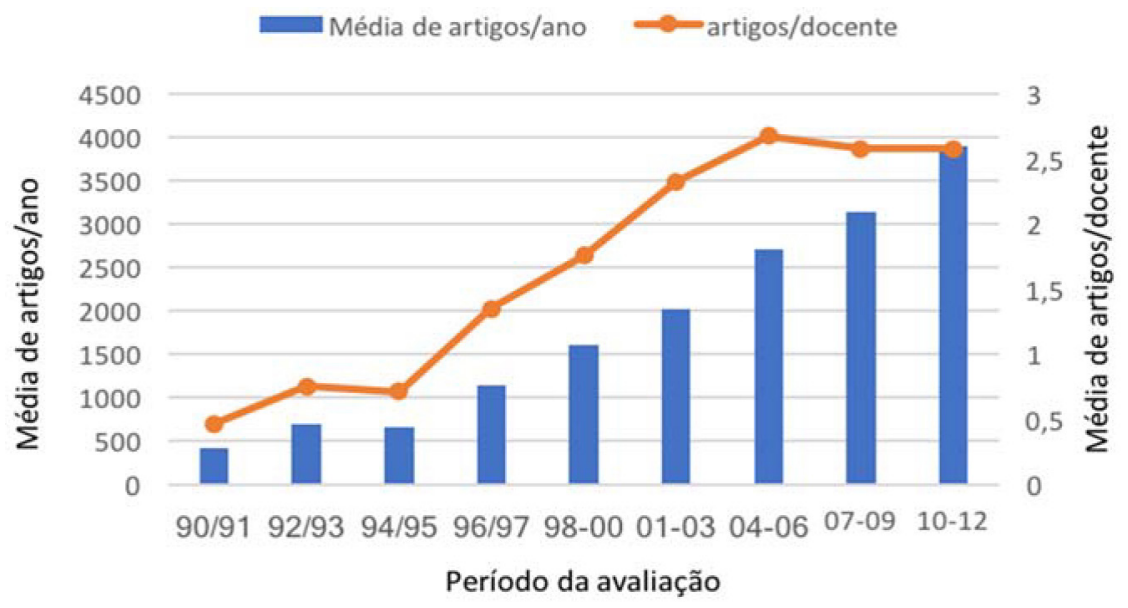

Figura 5. Evolução do número de artigos publicados da área (fonte: referências 11 e 22)

Tabela 3. Classificação da produção em periódicos da área de Química nos estratos do Qualis nas últimas quatro avaliações trienais, ${ }^{3,22}$

\begin{tabular}{|c|c|c|c|c|c|c|}
\hline \multirow{2}{*}{ Estrato } & \multicolumn{3}{|c|}{ Trienal 2004 (2001-2003) } & \multicolumn{3}{|c|}{ Trienal 2007 (2004-2006) } \\
\hline & FI (JCR) & $\mathrm{N}^{\circ}$ de artigos & $\%$ Artigos & FI (JCR) & $\mathrm{N}^{\circ}$ de artigos & $\%$ Artigos \\
\hline IA & $\geq 1$ & 3893 & 64,1 & $\geq 2$ & 3413 & 42,1 \\
\hline IB & $<1$ e $\geq 0,5$ & 1554 & 25,6 & $<2 \mathrm{e} \geq 1$ & 2894 & 35,7 \\
\hline IC & $<0,5 \mathrm{e} \geq 0,07$ & 122 & 2 & $<1 \mathrm{e} \geq 0,2$ & 1229 & 15,1 \\
\hline NA & & 91 & 1,5 & & 185 & 2,3 \\
\hline NB & & 112 & 1,8 & & 188 & 2,3 \\
\hline $\mathrm{NC}$ & & 305 & 5 & & 199 & 2,4 \\
\hline Total & & 6077 & & & 8108 & \\
\hline \multirow{2}{*}{ Estrato } & \multicolumn{3}{|c|}{ Trienal 2010 (2007-2009) } & \multicolumn{3}{|c|}{ Trienal 2013 (2010-2012) } \\
\hline & $\mathrm{FI}(\mathrm{JCR})$ & $\mathrm{N}^{o}$ de artigos & $\%$ Artigos & FI(JCR) & $\mathrm{N}^{\circ}$ de artigos & $\%$ Artigos \\
\hline A1 & $\geq 4$ & 596 & 6,3 & $\geq 4$ & 1343 & 11,5 \\
\hline A2 & $<4$ e $\geq 3$ & 1404 & 14,9 & $<4 \mathrm{e} \geq 3$ & 2956 & 25,3 \\
\hline B1 & $<3 \mathrm{e} \geq 2$ & 2890 & 30,7 & $<3 \mathrm{e} \geq 2$ & 2739 & 23,4 \\
\hline B2 & $<2 \mathrm{e} \geq 1,5$ & 2293 & 24,4 & $<2 \mathrm{e} \geq 1,5$ & 1950 & 16,7 \\
\hline B3 & $<1,5$ e $\geq 1$ & 1275 & 13,6 & $<1,5 \mathrm{e} \geq 1$ & 1333 & 11,4 \\
\hline B4 & $<1 \mathrm{e} \geq 0,5$ & 689 & 7,3 & $<1 \mathrm{e} \geq 0,5$ & 573 & 4,9 \\
\hline B5 & $<0,5$ e $\geq 0,1$ & 266 & 2,8 & $<0,5$ e $>0$ & 801 & 6,8 \\
\hline Total & \multicolumn{3}{|c|}{9413} & \multicolumn{3}{|c|}{11695} \\
\hline
\end{tabular}

ao desempenho discente que evidenciem a formação abrangente do pós-graduando. ${ }^{3,18}$ Portanto, os principais indicadores de cada um dos quesitos constantes na ficha de avaliação são baseados essencialmente em numeradores ligados ao desempenho discente (produção de artigos - com discentes e egressos até 5 anos, patentes, defesas de teses e dissertações, livros e capítulos de livros, atividades voltadas ao ensino, etc.) e em denominadores associados ao número de discentes no final do período e de docentes permanentes do programa.

A introdução de critérios de qualidade, incluindo o impacto da produção com discente em termos de número de citações das publicações, grau de internacionalização das pesquisas já enfocados na última avaliação pela área de Química, principalmente dos Programas 6 e 7, assim como a avaliação do índice H dos Programas, das 24 publicações em periódicos/ docente, do número de $\mathrm{PQ} / \mathrm{CNPq}$ (1A, 1B e Sênior), do número de pós-doutores do exterior, além de outros itens com enfoque em liderança científica permitem dimensionar não somente a qualidade dos resultados gerados pelos principais atores (docentes/discentes), mas também o interesse dos PPGs em estabelecerem redes de pesquisa colaborativas em nível nacional e internacional. Esses critérios de qualidade, certamente promovem ações concretas com vistas ao desenvolvimento de pesquisas competitivas em nível internacional, com forte viés interdisciplinar e inovador.

A área mostra evolução qualitativa e quantitativa nos últimos triênios na grande maioria dos critérios envolvidos na avaliação da formação de mestres e doutores. No período de 2010-2012, foram publicados 11.695 artigos dos quais 10.321 foram classificados em estratos > B2. Desses, aproximadamente $60 \%$ incluem discentes como autores. Uma característica da área é o número de registros de propriedade intelectual (patentes, direito autoral e demais modalidades) depositados, que no triênio 2010-2012 correspondeu a 365, mostrando um aumento de $34 \%$ em relação ao triênio anterior. No entanto, ainda são tímidos os indicadores referentes ao licenciamento desses registros de propriedade intelectual. Foram 16 patentes concedidas, 10 licenciamentos e docentes de 3 programas recebendo royalties no triênio 2010-2012. ${ }^{3}$ A qualificação das pesquisas na fronteira do conhecimento deve-se em grande parte às iniciativas da CAPES que 
culminaram nas discussões para a elaboração nos Planos Nacional da Pós-Graduação para a melhoria da qualidade da pós-graduação no país, assim como no caráter multi e interdisciplinar experimentado pela área de Química. Em resposta a essas perspectivas a área não distingue entre um periódico claramente identificado como da área de Química em relação a qualquer outra área do conhecimento na estratificação do Qualis periódicos. Dessa forma, sempre foi considerado positiva e desejável a publicação em periódicos qualificados nas diferentes áreas e a participação de docentes de outras áreas nos programas de Química e vice versa. Contudo, ainda há muitas assimetrias a corrigir, principalmente com relação à distribuição da pós-graduação no território nacional. Apesar do crescimento exponencial em múltiplos indicadores relevantes, um dos principais desafios da área continua sendo avançar na consolidação dos cursos, especialmente nas regiões Centro-Oeste e Norte. No sentido de sedimentar a ideia das redes de pesquisa interdisciplinares, contribuir para a diminuição de assimetrias e aumentar as interações entre os PPGs e grupos de pesquisa com vistas à qualificação da formação de recursos humanos, a coordenação de área de Química propôs a Diretoria de Projetos e Bolsas (DBD) da CAPES a implementação de uma proposta piloto de mobilidade de discentes de cursos de mestrado com nota 3 para os programas de pós-graduação 6 e 7 da área. Todos esses parâmetros e iniciativas, buscam incrementar o número de mestres e doutores com foco na qualidade da produção científica, tecnológica e na internacionalização. Com isso, é interessante também ampliar o número de estudantes e pesquisadores estrangeiros junto aos PPGs, especialmente das Universidades reconhecidamente de classe mundial.

Nos últimos anos a avaliação da pós-graduação incorporou dentre os critérios, o quesito inserção social. Nessa premissa, a integração dos PPGs da área com o ensino médio, a avaliação do destino dos egressos e alguns itens da produção científica com enfoque na difusão do conhecimento são valorizadas. Portanto, atividades de popularização da ciência e de ensino, principalmente voltadas para a divulgação de material didático de qualidade e divulgação científica que possam integrar e cooperar com escolas de educação básica, assim como outras atividades, incluindo oficinas, visitas a laboratórios, museus, e exposições de ciências contribuem sobremaneira para a integração das atividades da pós-graduação com o ensino médio. Muitos docentes dos programas de pós-graduação da área participam ativamente das atividades didáticas de graduação de formação dos licenciados. Essas atividades têm demonstrado minimizar a evasão nas instituições de ensino superior, implicando na fixação de professores de Química nas Escolas de Ensino Médio e no despertar da vocação desses jovens para o magistério de Ensino Médio.

Outro critério do quesito inserção social avaliado é a interação com o setor produtivo e governamental. Atividades como o registro e licenciamento de propriedade intelectual e a extensão tecnológica, bem como o incentivo à criação de empresas tipo spin off de grupos de pesquisa passaram a ser valorizadas. Desta forma, pretende-se que o know-how e a infraestrutura física dos laboratórios de grupos de pesquisa sejam transferidas para a sociedade de forma a auxiliar o desenvolvimento de serviços, processos e produtos inovadores. Além de fomentar essas atividades nos programas acadêmicos, a Área de Química vem incentivando, também, a criação de cursos de Mestrado Profissional voltados para desenvolvimento científico e tecnológico em parceria com indústrias químicas. De fato, atualmente existem dois cursos, um na USP/SP e outro na UFSCAR, os quais apresentam excelentes resultados na aproximação da acadêmica com o mercado, auxiliando na capacitação de profissionais que já atuam em empresas e que buscam na universidade auxílio para resolver gargalos tecnológicos. Levando-se em conta a importância da indústria química e do agronegócio na economia Brasileira, acredita-se que exista um potencial enorme de crescimento do número de cursos de mestrado profissional na Área de Química e espera-se que os dois atualmente existentes possam servir de exemplo e inspiração para o surgimento de outros nas diferentes regiões do país.

A avaliação do destino dos egressos já é uma realidade e fornecerá uma visão qualitativa da formação de recursos humanos pelos PPGs da área, na qual a análise do resultado pode ser privilegiada.

O período da quadrienal, além da retração nos recursos para bolsas e custeio, foi marcado por muitas mudanças, inclusive no comando da CAPES e das suas diretorias. Nesse sentido, o CTC-ES da CAPES procurou sempre avançar no processo de avaliação com cautela na implementação das mudanças. Nesse sentido, as fichas de avaliação do programas acadêmicos e profissionais mantiveram-se as mesmas utilizadas nos dois últimos triênios. Entretanto, essas fichas não se mostram adequadas para avaliar programas de mestrados profissionais em rede nacionais de capacitação de professores de ensino fundamental e médio (PROFMAT, PROFIS, PROFLETRAS, etc.). Portanto, uma ficha de avaliação específica para esses programas foi concebida e, pela sua adequação, foi facultado às áreas a utilização das mesmas na avaliação dos programas em rede com seis ou mais instituições. ${ }^{23}$ Essa ficha será usada pela área na avaliação do programa multicêntrico de Química de Minas Gerais. Além da ficha, fará parte da avaliação a análise de questionário respondido pelos egressos no período da avaliação quadrienal e coordenadores das unidades associadas. ${ }^{18}$ No caso da área de Química, a análise de questionário respondido pelos egressos no período da avaliação quadrienal também será usada para a avaliação dos programas de mestrado profissional. A avaliação posterior do resultado da utilização da nova ficha de avaliação e da consulta aos egressos será importante na discussão para possível reformulação das fichas de avaliação dos demais programas acadêmicos e profissionais.

\section{CONSIDERAÇÕES FINAIS}

Como discutido nesse artigo, as futuras metas já esboçadas no último PNPG e os aspectos que na atualidade fazem parte da agenda nacional e internacional das atividades de pesquisa envolvidas na formação de recursos humanos e na avaliação de seus resultados, devem e estão sendo implementadas e discutidas com os PPGs da área. Para que as principais metas dos PPGs da área sejam alcançadas, seminários de discussão devem fazer parte da agenda de comunicação entre os PPGs e a coordenação de área. Esse mecanismo tem sido adotado nos últimos anos e incentivado não somente pelos seminários promovidos pela CAPES dentro do calendário de acompanhamento e avaliação, mas também pelos eventos organizados pela SBQ envolvendo o fórum de coordenadores. Essas iniciativas certamente aproximam os PPGs e possibilitam compartilhar dúvidas, soluções e atividades acadêmico/científicas em cooperação. Essas atividades permitem ainda discutir a melhoria da qualidade de formação dos pesquisadores brasileiros e romper as assimetrias regionais.

É importante destacar que a Química é uma das áreas que mais cresce em termos de publicação e citações/artigos no Brasil, mas deve imprimir ações para melhorar o impacto de suas publicações e sua posição no cenário científico mundial. Esse crescimento está alinhado com a expansão dos PPGs da área de química no país e contribuiu sobremaneira também para a diminuição das assimetrias. Com isso, a criação de novos cursos nas regiões Norte, Nordeste e Centro-Oeste possibilitaram a introdução de temas regionais na execução de projetos de teses e dissertações, de forma a propiciar uma maior interação dos PPGs com problemas regionais e com enfoque em áreas estratégicas para o país. É importante destacar o forte investimento dos órgãos de fomento, incluindo a CAPES, CNPq, FINEP e FAPS, no financiamento da pesquisa no país. Com 
isso, o parque de equipamentos atualmente disponibilizado para a pesquisa na pós-graduação da área, assegura qualificada infraestrutura e contribui para a implementação e/ou consolidação das redes de colaboração entre pesquisadores que contribuem para a qualificação da produção científica e o avanço no processo de internacionalização dos PPGs da área. $\mathrm{O}$ avanço na melhoria da infraestrutura de equipamentos trouxe também novos desafios para o sistema de pesquisa do país. Falta infraestrutura física e de pessoal para alojar, manter e operar grandes equipamentos. Tais necessidades se configuram em um dos principais gargalos e desafios em CT\&I nos próximos anos. Portanto, o equacionamento dessas questões é de fundamental importância para manter a pesquisa experimental competitiva em nível internacional, de forma a qualificar a formação de recursos humanos. O PNE preconiza que até 2024 os PPGs do país deverão formar 60.000 mestres e 45.000 doutores/ano nas diferentes áreas do saber. Para tanto, é imprescindível que as agências reguladoras de CT\&I depositem um novo olhar na implementação de políticas nas suas linhas de financiamento para tornar esses desafios realidade. Nesse contexto, a área deve também discutir como aumentará a formação de recursos humanos imprimindo qualidade. Para tanto, propostas inovadoras devem fazer parte de futuros APCNs, trazendo assim novas oportunidades para a criação de cursos de mestrado diferenciados em regiões que apresentam demanda na área e ainda não estão representadas, assim a criação de curso de doutorado em programas de mestrado que apontam novas perspectivas. Como já mencionado, a Química como ciência central tem forte interação com áreas afins, propiciando a formação de recursos humanos com forte enfoque interdisciplinar, refletindo na qualificação da produção científica, na autonomia desses profissionais e na inovação como produto da criatividade inerente a esse processo. A indução de novas propostas na modalidade mestrado e doutorado profissional poderão aproximar os PPGs da área às ações dos setores públicos e públicos/ privados e formar recursos humanos para contribuir não somente para o desenvolvimento tecnológico, mas também na melhoria do ensino fundamental e médio. O PROFQUI pode aproximar a área a essa realidade. Essas novas perspectivas preconizadas no PNPG (2011-2020) e PNE (2014-2024) trazem em seus bojos um novo olhar para a avaliação dos PPGs da área que deve valorizar a qualidade e a análise do impacto dos seus resultados para a sociedade. Com isso, novas abordagens com enfoque em aspectos qualitativos contribuem para a formação de recursos humanos contemporâneos, capazes de responder aos principais desafios da sociedade brasileira e mundial. A área já introduziu critérios de qualidade na avaliação que visam dimensionar o impacto de suas pesquisas. Esses critérios incluem a avaliação do nível de internacionalização das pesquisas desenvolvidas nos PPGs, tais como, índice $\mathrm{H}$ do programa, análise qualitativa de um subconjunto da produção científica com a participação discente, além de outros itens com enfoque em liderança científica. A análise do destino dos egressos do Programa pode também trazer uma visão qualitativa dos PPGs da área. Diante dessas perspectivas, a área considera de fundamental importância introduzir formação qualificada e de fronteira a seus egressos para que sejam capazes de produzir conhecimento científico e de inovação tecnológica e formar recursos humanos que possam responder aos principais desafios que a sociedade demanda.

\section{AGRADECIMENTOS}

À Sociedade Brasileira de Química pelo convite, à Professora Rita de Cássia Barradas Barata pela leitura do manuscrito e sugestões e ao Fabricio Rocha Flores pela confecção do mapa do Brasil.

\section{REFERÊNCIAS}

1. CAPES 60 anos. Revista Comemorativa, 2011. Disponível em: https:// www.capes.gov.br/images/stories/download/Revista-Capes-60-anos.pdf acessada em Março 2017.

2. http://www.capes.gov.br/avaliacao, acessada em Março 2017.

3. Relatório de Avaliação Trienal 2013. Disponível em: https://docs. google.com/viewer?a=v\&pid=sites \&srcid=Y2FwZXMuZ292L mJyfHRyaWVuYWwtMjAxM3xneDo 3YzJkNjg2NThjZmIyNTM1, acessada em Março de 2017.

4. PLANO NACIONAL DE PÓS-GRADUAÇÃO (PNPG) 2011-2020, Vol 1, 2010. Disponível em : http://www.capes.gov.br/images/stories/ download/Livros-PNPG-Volume-I-Mont.pdf, acessada em Março 2017.

5. Giacomazzo, G. F.; Eccos Revista Científica, 2015, 37, 93.

6. de Andrade, J. B.; Schor, H. H. R.; do Nascimento, M. A. C.; Giordan, M.; Brocksom, T. J.; Aguilera, F. J. N.; Barreiro, E. J.; Quim. Nova 1995, $18,97$.

7. Brocksom, T. J.; de Andrade, J. B.; Quim. Nova 1997, $20,29$.

8. da Gama, A. A. S.; Nome, F. J.; Machado, J. C.; Quim. Nova 1999, 22, 443.

9. Pinto, A. C.; de Andrade, J. B.; Quim. Nova 1999, 22, 448.

10. Ferreira, V. F.; Quim. Nova 2002, 25, 715.

11. da Gama, A. A. S.; Cadore, S.; Ferreira, V. F.; Quim. Nova 2003, 26, 618.

12. Cadore, S.; de Andrade, J. B.; Quim. Nova 2007, 30, 1435.

13. Pinto, A. C.; Cunha, A. S. S.; Quim. Nova 2008, 31, 2221.

14. Pinto, A. C.; J. Braz. Chem. Soc. 2008, 19, IV.

15. Pinto, A. C.; J. Braz. Chem. Soc. 2012, 23, 1410

16. Nobrega, J. A.; J. Braz. Chem. Soc. 2013, 24, 1551.

17. http://www.capes.gov.br/component/content/article/44-avaliacao/4634quimica acessada em Março 2017.

18. http://www.capes.gov.br/images/documentos/Documentos_de_ area_2017/04_QUIM_docarea_2016.pdf acessada em Março 2017.

19. https://sucupira.capes.gov.br/sucupira/public/consultas/coleta/programa/ listaPrograma.jsf, acessada em Março 2017.

20. http://www.capes.gov.br/36-noticias/6908-capes-divulga-resultado-finalda-avaliacao-trienal-2013-apos-analise-de-recursos, acessada em Março 2017.

21. Barata, R. Revista Brasileira de Pós Graduação 2016, 13, 13.

22. http://www.capes.gov.br/avaliacao/permanencia-no-snpg-avaliacao/ avaliacoes-anteriores acessada em Março 2017

23. PORTARIA N ${ }^{\circ}$ 59, DE 21 DE MARÇO DE 2017 CAPES. Disponível em: http://capes.gov.br/images/stories/download/avaliacao/27032017Portaria-59-21-03-2017-Regulamento-da-Avaliacao-Quadrienal.pdf acessada em Abril 2017. 